THE 13th INTERNATIONAL CONFERENCE OF

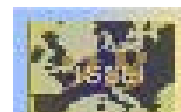

International Society for the Study of European Ideas

in cooperation with the University of Cyprus

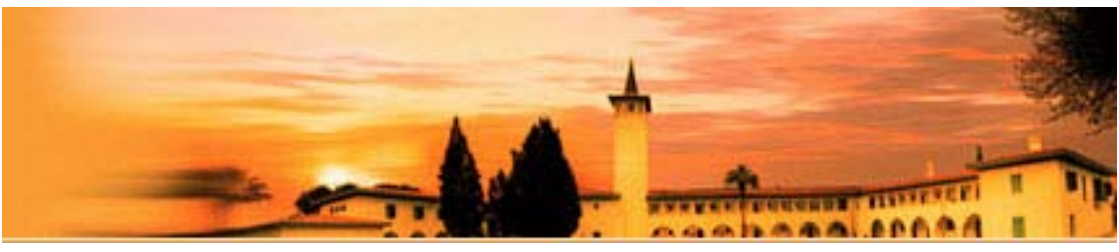

\title{
Public Space and Embodiment
}

James Mensch, Faculty of Humanities, Charles University

Hannah Arendt's notion of public space is one of her most fruitful, yet frustrating concepts. Broadly speaking, public space is the space where individuals see and are seen by others as they engage in public affairs. It is, thus, the space of the town hall meeting, the legislative assembly or any of the other venues where public business is done. What makes this concept so fruitful is that it gives us a way to phenomenologically analyze political freedom. Such freedom, as Arendt points out, requires public space since it is “manifested only in certain ... activities," namely, those "that could appear and be real only when others saw them, judged them, remembered them.” Thus, for the ancients, "the life of a free man needed the presence of others. Freedom itself needed, therefore, a place where people could come together - the agora, the market-place, or the polis, the political space proper" $(O R, 31){ }^{\mathrm{i}}$ This need points to the fact that the being of political freedom depends on its appearing. As Arendt writes, such freedom consists of "deeds and words 
which are meant to appear, whose very existence hinges on appearance" $(O R, 92)$. Given this, a fruitful way to study political freedom is through the study of such appearing. The freedom whose existence depends on appearing is, by definition, a subject of phenomenological inquiry. ${ }^{\mathrm{ii}}$

The frustration comes in when we apply Arendt's insights to our present political situation. Here, the result is almost entirely negative since Arendt claims that public space and its corresponding freedom have largely disappeared from the modern world. This is because of their tie to "action," that is, to the public activity of conducting public affairs. Arendt sharply distinguishes this action, which consists in "acting and speaking together," from "labor" and "work" (HC, p. 198). ${ }^{\text {iii }}$ The domination of modern society by the latter leads to the atrophy and near disappearance of both public space and political freedom. "Labor," which she takes as essentially private, has no place for public space, replacing it with the workplace of the factory or office. As for "work," which is her term for fabrication, it reduces the public realm to the "the exchange market, where [the fabricator] can show the products of his hand," this being, in today's terms, the spaces of the market place and mall (HC, p. 160). Lacking a proper public realm, political freedom, whose "actual content ... is participation in public affairs, or administration of the public realm," becomes, itself, unavailable $(O R, 32)$. It is replaced by a series of negative liberties that are "meant to institute permanent restraining controls upon all political power" $(O R, 108)$. Freedom, in other words, comes to mean freedom from (rather than participation in) political power. In Arendt's terms, genuine political freedom becomes the "lost treasure" of "the revolutionary tradition" (OR, 215). 
In what follows, I am going to argue that this pessimistic assessment follows from Arendt's exclusion of labor and work from the public realm. Against Arendt's claim that such activities are essentially private, I shall argue that they, like action, manifest our embodied being-in-the-world. Arendt fails to see this because she consciously adopts the ancient prejudice against embodiment. Once we do take account of our embodiment, however, we have a way of phenomenologically analyzing the public space that includes all the elements that Arendt saw as making up our human condition.

\section{§1. Arendt's Critique of Embodiment}

As Arendt observes, the traditional "contempt for labor" $(H C, 81)$ was for the "slavish nature of all occupations that served the needs for the maintenance of life" ( $H C$, 83). Essentially, it was contempt for our animality. According to Arendt, for the ancients, "[w]hat men share with all other forms of animal life was not considered to be human.” In fact, the condition of slavery "carried with it a metamorphosis of man into something akin to a tame animal” $(H C, 84)$. Arendt's adoption of this view is signified by her remarking "that the use of the term 'animal' in the concept of animal laborans ... is fully justified. The animal laborans is indeed only one, at best the highest, of the animal species which populate the earth” (ibid.). Behind this contempt was the notion of man as an animal possessing the ability to speak and, through this, the ability to construct a common, public world with his interlocutors. The laboring condition, however, reduces us to the privacy of the body. Labor accomplishes its action, not through speech, but through bodily exertion. Now, as Arendt observes, "Nothing ... is more private than the bodily functions of the life process" $(H C, 111)$. No one can eat for you, sleep for you or perform a host of other organic functions for you. This very privacy makes the laborer to 
be "worldless." In her words: "The animal laborans does not flee the world but is ejected from it insofar as he is imprisoned in the privacy of his own body, caught in the fulfillment of need in which nobody can share and which nobody can fully communicate” (HC, 118-19). Because of this, the laborer is "incapable of building or inhabiting a public, worldly realm” $(H C, 160)$.

A parallel critique is made of "work," or fabrication, "which adds new objects to the human artifice” (HC, 88). Such objects, such as clothing, furniture, etc., do create a "sheltering world." Those who produce them leave their workplaces to exchange them. They meet and have a public realm, "the exchange market.” This realm, however, is infected by the privacy of the body. For John Locke, "the privacy of appropriation" through labor makes its products the property of the laborer. According to Arendt, this argument receives its plausibility from the privacy of "the bodily functions of the life process. ${ }^{\text {iv }}$ It is, in other words, the privacy of the laboring body that makes the products that the workman produces into private property. The public realm, in which such property is exchanged, thus mediates the privacy of the workplace and that of the private places, the homes, where they are used. Such products, in other words, are not common but owned.

For Arendt, the only mode of entrance to the common world occurs through "action," which consists of "speech as a means of persuasion." "To be political, to live in a polis," she writes, "meant that everything was decided through words and persuasion and not through force” $(H C, 26)$. In fact, “Aristotle’s definition of man as a zöon politikon [a political animal] ... can be fully understood only if one adds his second famous definition of man as a zöon logon ekhon ['a living being capable of speech']” (HC, 27). This is be- 
cause to be political is to engage in "a way of life in which speech and only speech made sense and where the central concern of all citizens was to talk with each other" (ibid.). The result of such talk is the presence of public space. This is "the space where I appear to others as others appear to me,” that is, "the space where men ... make their appearance explicitly" (HC, 198-99). "Most men ...” she adds, “—the slave ... the laborer or craftsman ... the jobholder or businessmen in our world—do not live in it.” The fact that they do not means that they are "deprived of reality, which humanly and politically speaking, is the same as appearance." Her point is that "the reality of the world is guaranteed by others, by its appearing to us all” $(H C, 199)$. Since we cannot see through one another's eyes, the only way we can grasp the world that appears to us all is through the discourse that links us to others. We report what we experience and take it to be real when our reports are confirmed by others. In excluding labor and work from such confirmatory discourse, she thus deprives their practitioners of the full human reality of what appears. At the basis of this exclusion is the embodied nature of their activities. The body they employ imposes a privacy that is incapable of such discourse.

\section{§2. Embodiment and Appearing}

Arendt writes that "action and speech create a space between the participants which can find its proper location almost anytime and anywhere” (HC, 198). As such, this space, like the words that create it, has a disembodied character. Unlike labor and work, which are performed, not for themselves, but for what they accomplish or produce, action's goal is its own continuance. The free discussion that opens up public space has as its goal the maintenance of such space through its own appearing. Thus, as Arendt writes, in political life, the 'product' is identical with the performing act itself." In this it 
is like "the performance of the dancer" $(H C, 207)$. On the one hand, we cannot tell the dancer from the dance. On the other, the point of dancing (the 'product' it produces) is the dance itself. Thus, both the dance and the dancer are simultaneously actualized.

This example betrays the difficulty hidden in her account: Dancing is the movement of the body. To dance, one must be embodied. The same holds for speaking. To speak is to give voice, which involves the breath and the voice box. The speaker, moreover, must be clothed and fed by the workman and the laborer. Furthermore, since the speakers are embodied, they need "a place where people [can] come together-the agora, the market-place, or the polis,” all of which, presumably, need to be constructed. None of these constraints, which involve the necessities of labor and work, would be present for disembodied speakers. Speech, in fact, is necessary to overcome the physical divide between speakers that embodiment brings. For disembodied beings, this necessity would fall away. Like angelic intelligences, they would know immediately one another's minds. Given this, the appearing that speech makes possible presupposes embodiment. It points, in fact, to the ways in which embodiment and appearing, in particular the appearing of public space, imply each other.

At the root of this implication is the fact that the body is much more than the private sphere of its organic needs. It is also the ability—-the "I can" — to fulfill them. This "I can," in fulfilling these needs, also discloses the world. Doing so it intertwines the self with the world, making the self, in its "I can," part of the appearing world. To see this, we have to trace a few of the levels in which our "I can" both situates the appearing world "in” us as a place of disclosure and situates us "in" this disclosed world. The most basic level of this situating "I can" is that of the "I can sensuously perceive something." As 
Merleau-Ponty writes in describing this level, when I see an object, I believe that "my vision terminates in it, that it holds and stops my gaze with its insurmountable density.” The object is out there in the world, a world that includes me as one of the visible objects. "Yet,” he adds, “as soon as I attend to it, this conviction is just as strongly contested by the very fact that this vision is mine" (VI, pp. 4-5). ${ }^{\mathrm{v}}$ I believe that my perception "is formed this side of the body" - my body. Thus, I close my eyes and the world disappears. I open them and it is again visually present along with my body. Holding "on to both ends of the chain," I assert "I am in the world and the world is in me” (VI, p. 8).

Behind this belief is the fact of my being an embodied perceiver. In my bodily being, I provide the venues for the world's appearing. Using the word tapisser, to cover, drape, line or wallpaper, Merleau-Ponty expresses this by asserting, “our flesh lines and even envelops all the visible and tangible things" (VI, p. 123). Thus, we "line" the world with visual qualities through our eyes, with tactile qualities through our sensitive skin, and so on. Doing so, our embodied being provides measures "for being, dimensions to which we can refer it” (VI, p. 103). In other words, through our flesh, we can refer to the sensible aspects of being. We can measure it along the axes or dimensions of its colors, tastes, sounds, smells, roughness and smoothness (ibid.). The world that is present through our embodiment is, however, the very world that our embodiment, as something that appears, thrusts us into. This means, Merleau-Ponty writes, "my eyes which see, my hands which touch, can also be seen and touched ... they see and touch the visible, the tangible from within" the visible and tangible world (VI, p. 123). Similarly, the flesh that "lines and even envelops" the things of this world is "nevertheless surrounded" by them (ibid.). 
Our body does not just "line" the world through its senses. The "I can" of its bodily mobility also provides a space for the world's disclosure. As Merleau-Ponty writes, "it is literally the same thing to perceive one single marble and to use two fingers as one single organ.” ${ }^{\text {vi }}$ Our perception of the marble is one with a set of bodily acts, those of reaching over, picking up and handling the marble. It is by rolling it between our fingers that we perceive its different colors and determine its hardness and smoothness. Such activities are part of the ways in which we "line" the world. They form part of the "place" of the disclosure of the world. As part of our bodily "I can," this "place" is within us and also within the world.

The same point holds when we proceed up another level and expand this "I can" to include our projects. The disclosure of the world's senses is not simply a matter of beholding and manipulating objects. It arises from the practical projects such abilities make possible. Thus, as we employ various objects for our projects, we get the sense of what they are for. Their pragmatic meanings are given by their purposes. A hammer, for example, is understood when we use it to drive in a nail; a glass reveals its sense when we use it to drink from. Engaging in such projects, we are both in the world and disclosive of it. Here, the place of such disclosure is our purposeful activity. As embodied, such activity is in the world. The world, however, is also within this activity since the activity is what "lines" the world by providing us with a new set of dimensions for its appearing. The same intertwining characterizes the senses that our projects disclose. They, too, are within us and external to us. They are within us since they guide our actions as we employ various objects for particular purposes. Yet our action externalizes them. When we use a hammer to drive in a nail, the pragmatic meanings we assign to these objects are apparent 
to others. The body-project that discloses these senses thrusts them into the public realm. They become senses inherent in a project that is there for others to observe.

Projects, of course, are not just individual but also collective. As we grow up, the "I can" of our initial projects becomes expanded to an "I can" that functions with the "I can” of others as we engage in various activities. Such collective projects are correlated to the ways we disclose the world, i.e., "line" it by providing a new set of dimensions for its appearing. This appearing includes our own appearing as the accomplishers of these collective projects. Thus, the "I can" play the violin as a member of a string-quartet discloses me as a member of this ensemble. It is, correspondingly, also the disclosure of a world, that of the music written for the players, that can only exist as a correlate of our activity. Similarly, the member of an aboriginal hunting party discloses the world of the hunt as well as himself as a participant in it.

As we pass through these levels of the "I can," the sense of the body that engages in projects extends its sense. The "I can" that defines its activity includes the implements it uses — the glass for drinking, the hammer that drives the nail, etc. Its functioning, in other words, is in terms of the senses it discloses. As such, it is situated and historical. The "I can" that includes talking on the telephone extends the voice to speak over great distances. That which includes driving a car extends the "I can" of its mobility. The same holds for the internet, the smart phones and social media that were involved in the actions of the "Arab Spring." The collective projects and disclosures of collective worlds that these made possible would not have been possible a dozen years ago. ${ }^{\text {vii }}$ Such media also have to be included among the ways that we "line" the world, providing ways for the world and ourselves to appear. 
For Arendt, as we have seen, appearing is primarily tied to language. It is what creates the public space between individuals—-in her words, "the space where I appear to others as others appear to me," that is, "the space where men ... make their appearance explicitly” (HC, 198-99). “Most men” as we cited her, “do not live in it.” The embodied nature of their activities prevents this. This opposition of language to embodiment forgets the role of the body in our learning a language. Such learning occurs in the context of our initial body-projects. For example, we first learned the word "spoon” when our caregivers, speaking to us, taught how to use a spoon to eat. Its meaning was given by its function, and its function was set by the particular projects that our caregivers and companions introduced us to. As is obvious, the more multiple the projects an object is involved in, the more multiple are its meanings. Thus, besides meaning something to eat with, a spoon can also mean something to ladle sugar with, to measure with, to stir with, and, for children, something to dig in the garden with. Each new use discloses a new aspect of it and adds to what comes to mind in connection with the word.

This same holds generally. The basic senses that make up our language come from the projects that disclose the world. The commonness of our projects, for example, our common use of the spoon to eat with, gives us the commonness of our senses. Such commonness is verified each time we engage in our collective projects, i.e., coordinate our activities to achieve a common end. Such projects disclose a common world, one constituted by the senses we share. Given this, Arendt's assertion that the "the reality of the world is guaranteed by others, by its appearing to us all” does not point to the distinction between embodiment and language. On the contrary, this common appearing 
indicates the commonality of our embodiment, i.e., the commonality of the organic and the technologically extended "I can” of our common projects.

\section{§3. Embodied Public Space}

As the above analysis indicates, appearing has to be thought in terms of embodiment. The body is not private-i.e., worldless. It is what thrusts us into the world. It makes our being-in-the-world a place of the world's disclosure. The point can be put in terms of incarnation—of becoming flesh. The appearing world incarnates itself through our perceptual organs. It achieves its embodied, sensuous presence through their lining the world. By virtue of them, it has its weight, its texture, its sounds, colors and smells. These same organs also line our own bodily presence. We appear in this embodied world as embodied perceivers. The same point can be made with regard to all the other ways that we line the world through our projects and our language. They make the world appear as filled with pragmatic and linguistic senses. They make us appear within it as pragmatic and speaking agents.

Our intertwining with the world we appear in means that neither side can be thought apart from the other. Thus, we cannot speak of the sensuous world apart from our perceptual experience, an experience that presupposes our own existence as embodied perceivers. As embodied, we provide the place for its disclosure. Contrariwise, we cannot think of our existence as embodied perceivers apart from the sensuous world. This world is our place of disclosure. Appearing within it, our bodies can be examined and disclosed along with all other appearing objects. The same pattern of reciprocal disclosure holds for all the other levels of our embodied "I can.” The world of the aboriginal hunting party, for example, is inexplicable apart from the activities that disclose it. Such activities, however, 
draw their sense from this world. Similarly, we cannot grasp the functioning of language apart from the world with the objects and activities that language names and describes. Such objects and activities, however, have their intersubjective presence only through language. They appear as common only by virtue of our expressing to each other what we perceive.

In our concrete, human reality, all of the levels of the "I can” are intertwined with each other. This means that not only do they disclose the world by embodying it along a particular sets of dimensions, they also embody and, hence, disclose one another. Thus, the sensuously present senses of the "I can perceive" are required for the pragmatic senses that our individual projects disclose, which themselves are required for the senses that our collective projects make apparent. The functioning of our language is tied to such senses and is, in fact, what makes them genuinely intersubjective. Genetically regarded, there is, here, an order of precedence. We must first perceive before we can manipulate perceivable objects. We have to be able to manipulate them to engage in our projects, and so on. Once established, however, all the levels are intertwined. The sensuous objects we now see are immediately taken as intersubjectively present. They appear to us bathed in language. Their linguistic and sensuous presence is intertwined.

The same pattern holds when we turn to Arendt's trinity of labor, work, and action. To view them in terms of embodiment is to understand them in terms of the "I can." So regarded, they are three ways in which we disclose the world, three ways in which we construct the public space that we inhabit. Such public space can only be understood in terms of their intertwining. Each of them embodies the others. Doing so, they serve as places of disclosure for each other-i.e., as the places for their reciprocal appearing. This appearing 
occurs in conjunction with our disclosure of the world. We disclose the world even as we disclose the elements of our human condition. The public space we share is, in fact, the result of such disclosure.

Since all these elements are part of our human condition, the disclosure of each can be seen as calling the others into question. It points out the one-sidedness of their accounts of our condition. Thus, the one-sidedness of labor comes from the fact "that," as Arendt writes, "it leaves nothing behind, that the result of its effort is almost as quickly consumed as the effort is spent" (HC, 87). Work, with its focus on products that outlast the laboring process calls this perspective into question. It points out that the very transience that marks it means that the laboring process leaves no lasting, sheltering world behind. Work, however, also has its one-sidedness. It fails to realize that the world it creates only lasts through being maintained and repaired by labor. As for action, its onesidedness springs from its disdain for embodiment and, hence, for labor and work. In classical Athens, for example, craftsmen were treated with aristocratic contempt, while labor was degraded to the point of slavery. This separation of action from making and labor deprives societies of the permanence and organic vitality necessary for their continuance. At the extreme, it pits the few who have the leisure to engage in political life against the many that are excluded. The strikes and disruptions this result in can be understood as labor and work attempting to disclose its one-sidedness.

To overcome this, we have to open up public space. All the elements of our condition must participate in the discourse that creates this space. By pointing out their own contributions to it, they must be free to call one another into question. A wellfunctioning public space vibrates with different accounts. It involves the continuous dia- 
logue between them. Such public space is not a "lost treasure" of "the revolutionary tradition.” It is not the case as Arendt writes, that "[t]he relationship between a ruling elite and the people, between the few, who among themselves constitute a public space, and the many, who spend their lives outside it and in obscurity, has remained unchanged" $(O R, 277)$. When conceived in terms of embodiment, such space includes the historical development of our "I can.” In our day, this involves its extension through smart phones, uploading videos and the world-wide reach of the internet. This extension of public space points to the democratization of "action" in the most fundamental of the senses that Arendt assigns to it — that of showing who and what those who engage in action are. It shows that public space is not static, but rather a continuing gift of our embodied ability to disclose. 


\section{ENDNOTES}

i Hannah Arendt, On Revolution (London: Penguin Books, 1990), cited throughout as OR.

ii As an example of such a study, see James Mensch, “Public Space,” Continental Philosophy Review, 40:1, March, 2007, 31-47.

iii Hannah Arendt, The Human Condition (Chicago: University of Chicago Press), 1958, cited throughout as $H C$.

iv In her words: "Nothing, to be sure, is more private than the bodily functions of the life process ... labor ... is still close enough to the life process to make plausible the argument for the privacy of appropriation” $(H C, 111)$. This means: “The body becomes indeed the quintessence of all property because it is the only thing one could not share even if one wanted to” (112).

v Maurice Merleau-Ponty, The Visible and the Invisible trans. A. Lingis, Evanston, IL., Northwestern University Press, 1968, cited throughout as VI.

vi Maurice Merleau-Ponty, Phenomenology of Perception, trans. Colin Smith (London: Routledge \& Kegan Paul 1962), p. 205.

vii This conception of “our non-organic body” comes from Patočka. See Body, Community, Language, World, trans. Erazim Kohák (Chicago: Open Court, 1998), p. 50. 